$7-21-2011$

\title{
Making Pigs Local: Discerning the Sensory Character of Place
}

Brad Weiss

College of William and Mary, blweis@wm.edu

Follow this and additional works at: https://scholarworks.wm.edu/aspubs

Part of the Social and Cultural Anthropology Commons

\section{Recommended Citation}

Weiss, Brad, Making Pigs Local: Discerning the Sensory Character of Place (2011). Cultural Anthropology, 26(3), 438-461.

10.1111/j.1548-1360.2011.01106.x

This Article is brought to you for free and open access by the Arts and Sciences at W\&M ScholarWorks. It has been accepted for inclusion in Arts \& Sciences Articles by an authorized administrator of W\&M ScholarWorks. For more information, please contact scholarworks@wm.edu. 


\title{
MAKING PIGS LOCAL: Discerning the Sensory Character of Place
}

\author{
BRAD WEISS \\ The College of William and Mary
}

As regions go, central North Carolina might seem an odd choice to examine the complex relationships between "taste" and "place" invoked by the culinary concept of terroir. Although the region has its time-established foodways, a range of much-debated recipes, distinctive agricultural products and practices each with its loyalists, the demographic and political economic transformation of the state, especially in recent decades, has been striking. These transformations are especially apparent in the pork industry, no small irony given the centrality of pigs to the Carolinian (agri)culture imaginary. North Carolina has seen an astronomical increase in industrial pork production: from 2.6 million hogs grown in 1988, to over 8 million in 1997, to well over 18 million pigs in 2006. As recently as 1993 North Carolina was the fifth leading state for pork production in the United States; it now competes with Iowa for the status of leading pork producing state (see Iowa State University n.d.; North Carolina in the Global Economy n.d.). The devastating effects of industrialization on watersheds, soil nutrients, energy costs, labor, as well as pigs themselves, have been thoroughly documented (see Kaminsky 2005; Morgan 1998; Niman 2009). This radical transformation has generated a landscape of displacement, as small farms are increasingly consolidated under the contractual obligations of vertical integration, and long-standing methods of raising livestock give way to confined animal feeding operations (CAFOs; see Page 1997). Such industrialization characteristically undermines the kinds of depth 
and connoisseurship requisite for terroir (Trubek 2008), the "taste of place" valued among advocates of "Slow" and "local" foods.

But in the shadows of this displacement, many farmers, restaurateurs, and consumers are advancing an alternative. In no small part owing to the rising, widely mediated consciousness of the perils of the industrial food complex (Kenner 2009; Kingsolver 2008; Pollan 2006; Schlosser 2001), this same region has seen a significant growth of interest in alternatives to this production system. An important dimension of these alternatives is the expansion of pasture-raised animal production, and more specifically, the growth of pig farms that subscribe to sustainable practices. ${ }^{1}$ The market for pork from these farms is central to the surging interest in "local foods" in the Piedmont, the central region of North Carolina; as one animal scientist at NC State noted, "over the past five years, meat sales have been surging. Consumers want to buy pork from farmers" (Morrow 2005). Such pork is often marketed by producers, and sought out by consumers, specifically as a "local food." Indeed, when I told one farmer that Smithfield, the largest pork processor in the United States, with production facilities in North Carolina, was bringing out a line of "pastured pork" her response was, "That won't effect us; local will always trump any other label." And so, in the heart of a state thoroughly transformed by the dislocations wrought by industrial pork production, pasture-raised pork has become a central feature of the "local food" scene.

The political economic motivations of the pastured-pork market are unmistakable. Piedmont farmers and foodies alike are critically aware of the devastation, in particular the environmental degradations, wrought by the industrialization of pigs. At the same time, many historical issues of farming relating to labor, class, and race in hog farming here are less fully incorporated into the politics of "local food." The largely cosmopolitan producers and consumers of this niche-market pork, according to my recent survey research, describe themselves as committed to support for local farming systems, and oppose the perils, especially ecological, of the corporate, industrial food system. However, they rarely make reference to the problems of racial disparities that are rife in North Carolina agricultural production, or express concern for the condition of workers on "local farms" as often as they ask, for example, about animal welfare. To be sure, these cosmopolitans in the Piedmont are "progressive" in their politics, and often work assiduously to make local food more affordable, and provide outreach to underresourced consumers, including a growing Latino community, in the region. Nonetheless, participants in this largely white, "middle-class" movement do overlook some problems of inclusiveness, a point to which I return in my conclusion. 
My approach here is informed by the concerns of locavores for "sustainability" and "environmental justice," and I understand these concerns as part of a broader process through which social actors grapple with the places they construct and inhabit. I consider one specific feature of the relationship between pigs, an agricultural icon of the Piedmont, and the movement to promote "local foods," namely, the connection between "taste" and "place" as cultivated and embodied in the production, circulation, and consumption of pasture-raised pork. Ethnographic evidence drawn from working with farmers, chefs and restaurant workers, and consumers at farmers' markets from a number of sites in the Piedmont demonstrates how these sites are fields in which "place" is constructed in action and experience, and imbued with concrete meanings and orientations. Pasture-raised pigs (also referred to as "niche market," "heirloom," or "specialty breed” pork; Honeyman et al. 2006) provide an excellent entity through which to outline a field of participation among diverse actors, human and otherwise, whose activities constitute the "places" held to underlie "local food" processes, including tastes. Their porcine paths take us from the intimate gustatory pleasures of pork fat, to efforts to combat the dire social inequities of environmental, human, and animal degradation at the hands of industrialization.

Kate Pierson has been raising pastured pigs at Haw Branch Farm for over five years. ${ }^{2}$ On Haw Branch I have participated in all aspects of pig (re)production, from the daily care and feeding of over 250 pigs (among many other species), to tracking the development of a registered line of a specific heritage breed - the Ossabaw Island Hog - being revitalized on the farm. My experience with Haw Branch also entails marketing. Haw Branch pork is sold directly to restaurants, a few local grocery stores, and three farmers' markets in the Piedmont. I have worked alongside Pierson at a farmers' market since early 2009, and so gotten to know regular customers, as well as other pork vendors. Finally, my connections with Haw Branch afford me access to the restaurants in the region that feature Haw Branch products, and other pastured pork. I worked in the prep kitchen of a well known, Slow Food praised, restaurant during summer 2009. In all, I have worked on more than a dozen farms, and interviewed a dozen chefs in the region. The methodological scope of this project reveals how place is created through the paths forged by pigs in the Piedmont; and, in turn, how places made by these relations shapes the pigs (and their pork) in qualities ranging from their parental skills, to their genetic viability, environmental impact, and succulence.

North Carolina is also renowned for its exquisite pork barbecue. Each region (notably "Eastern" and "Western" which overlap in the Piedmont) has its recognized 
style of preparation, different sauces (Eastern vinegar and pepper based, excluding tomato, which is the base for Western style), cuts of pork (whole hogs vs. shoulders) and festivals celebrating the virtues of each. Even this cursory evidence suggests that, in North Carolina, the production and consumption of pigs is redolent of a concern with the specificities of places and tastes and their implicit interconnection.

Rather than assume these interconnections as a given feature of locality and foodways, I problematize such links between place and taste (as well as the very category "local food") by asking how places are constituted, and how taste becomes one of place's constituent qualities. "Local food" is widely celebrated here, and pastured pork may be a critical index of "locality," but these assertions beg the question of how "place" is established, and given the concrete, experiential qualities, through which it is grasped in social practice. More than an attempt to specify the qualities of "the local" and their relationship with distinctive foodways, or agricultural niches, I am concerned with what Lefebvre calls "the production of space”3 (Lefebvre 1991). What is valuable about Lefebvre's model is the way it combines attention to the political economic restructuring of everyday life under (neo)capitalism (Lefebvre's [1991:39] term), with considerations of the felt qualities of lived, bodily experience. I focus on these correlated concerns, and propose to follow the pig through its many places to show how pork production and consumption might reveal how a place's tastes are cultivated within what I call a shared, if also contested, sensory field. A taste for quality pork, at once an ancient tradition and an entirely new cuisine in the Piedmont, is being carefully crafted through a range of venues in a process attuned to the materiality of ecosystems, landscapes, animals, and meat; built through social relationships among farmers, craftsmen, and activists; cultivated in the educational mission of menus and market tastings, and, so, suffused in place. Exploring this sensory field within the production of space allows us to grasp how characteristic dimensions of place - above all tasteinvoked by "local food" advocates in the Piedmont have been remade by remaking pigs and pork.

\section{PLACES IN PERSPECTIVE}

The relationship between place and food, and qualities of taste in particular, has generated a great deal of interest in recent decades. Part of this interest derives from the work of environmental activists dedicated to "sustainability," who understand food as an expression of the resources - (agric)cultural and ecological — on which it draws (Berry 1990; Dover and Talbot 1987) "Eating is an agricultural act," as Berry famously puts it; or would be, were it not for the fact that industrialization 
has devastated the connections between farmers and eaters, stultifying the tastes of consumers:

The industrial eater is one who no longer knows that eating is an agricultural act, who no longer knows or imagines the connections between eating and the land, and who is therefore necessarily passive and uncritical — in short, a victim Berry (1990:153).

It is certainly the case that many "local food" activists in the Piedmont are motivated by these ecological, anti-industrial arguments. Such critiques form a cornerstone of efforts of farmers, chefs and others' efforts to regenerate robust connections between farms and eaters. Desirable as these objectives are, Berry's essentialized "connections between eating and the land" are problematic terms with which to approach linkages between taste and place in any kind of comparative (i.e., anthropological) framework. "Industrial eaters" inhabit a world that is not null, but, in fact, full of places. Such ecological perspectives presume that places have specific, intrinsic qualities (subtended by natural and cultural activities) that are expressed by eating, and so realized as taste. "Eating ends the annual drama of the food economy that begins with planting and birth" (Berry 1990:145). This is more a normative assertion than a claim that can be used comparatively. People eat and taste the world over. Understanding how the taste of food reveals what place is requires a broader perspective.

Recent anthropological and sociological work on the relationship between taste and place engages the cultural category "terroir" from a variety of perspectives (Barham 2003; Trubek 2008; Trubek and Bowen 2008). In her excellent recent review of the concept, Paxson notes that North American experiments with terroir represent a critical response to deterritorializing effects of industrial farming, just as ecological concerns motivate much food activism. But Paxson's perspective situates these environmental concerns within a wider project:

terroir provides American producers with an opportunity for reterritorialization, for drawing meaningful lines of connection among people, culture, and place to invest place anew with affective significance and material relevance. [2010:446]

She argues that connections between place (conceived in ecological, material, agricultural and cultural registers) and taste invoked by the term terroir are under construction ("reverse-engineered" as Paxson puts it, with the French model as a goal) as the food system is reterritorialized. Taste's grounding in place, then, emerges within the construction of place. 
This process of (re)making place is the wider framework within which to situate the current interests and actions of the locavore movement. Places are suffused with experiential qualities (like taste), and provide a grounding for sociopolitical projects (Casey 1998). This is not a normative framework that assumes that only richly integrated social and natural regions constitute "expressive” places. Rather, I see place as a constitutive feature of human habitation (Casey 1998; Merleau-Ponty 1962). Defining the contours of the production of space, and modes of dwelling, allows us to specify how a politics of food is spatialized. Why, for example, does opposition to industrialization, or commodity agriculture invoke place as a remedy to this critical social problem? Why is "local food," among all legitimate rubrics for collective action, such an effective category? How are problems of industrialization, animal welfare, environmental degradation, or the exploitation of labor, spatial matters to which "locality" offers an alternative? Specifying how places are constituted, and the qualities with which they are imbued, helps us grasp the force of the politics of space entailed in appeals to locality.

Lefebvre's work on the spatial character of everyday life develops Marxian concerns with the relationship between production and consciousness. For Lefebvre, space is a social product, not merely a conceptual schema to be read, or decoded; or a physical "container" for social action. What he calls "three moments of social space" provide my heuristic point of departure. These moments are (1) Spatial practice, the various modes of activity through which subjects interact in and with spatial relations, assuring their production and reproduction; (2) Representations of space, ways of conceiving space and codifying it in objectified models, plans or schema; and (3) Representational spaces, "embodying complex symbolism, sometimes coded, sometimes not, linked to the underground side of social life" (Lefebvre 1991:33). This conceptual triad, which Lefebvre condenses as space as “perceived-conceived-lived” (Lefebvre 1991:40) is foundational to Lefebvre's discussion of the structure of everyday life. It incorporates conceptual schemata, material landscapes, as well as sensory qualities ("sensory-sensual space” 1991:212) borne by the "spatial body" (1991:194ff). As I assert, the sensory experience of taste informs the actions of, and can be produced by this spatial body. Here, I explore space as "perceived-conceived-lived" to characterize the conditions that permit "tastes" to evoke "places" for Piedmont advocates of "local food."

\section{HOW IS PLACE MADE?}

To suggest the complex character of "place" as a "perceived-conceived-lived" phenomenon, and demonstrate some of the ways that pigs and pork figure in this 
complexity, let me illustrate how "local pork" finds its way onto menus in the Piedmont. One restaurant, for example, features robust regional Italian dishesFarinata, Panetonne, an abundance of pancetta and guanciale. On each dining table is a small placard listing the produce procured at market that week, and the farms from which it's harvested. The chef is from the region, and hopes these touches will "remind diners of the Southern roots" of his establishment.

In 2009, I worked in the prep kitchen of a restaurant (which I call Monsoon) whose menu and signage highlight its affiliation with all things local, including its prominent place in the founding of the regional chapter of Slow Food. It features a Pan-Asian cuisine, with ingredients acquired, as much as possible (which is to say, about 80 percent), from North Carolina sources. When Monsoon participated in the James Beard Foundation fund-raisers in Manhattan it offered a picnic plate featuring deviled eggs, strawberry snow cones with candied fruit and marshmallow fluff, along with barbecue sandwiches. Although not indicative of the fare served up on a daily basis at Monsoon, the chefs told me that these foods were meant to highlight the regional offerings of the Piedmont - what could be more North Carolina than barbecue, and early season strawberries? - and to emphasize, yet again, the importance of "local food" to their operating ethos.

These two modest examples pose a question: What do we mean by place when we talk about its taste? Any unified notion of place as a "territory," geographical zone, or material ecology is incompatible with these examples of how "local foods" operate in practice. Restaurants emphasize attachments to a specific "local" network, a community of laboring farmers, artisanal meat processors, sustainable fisheries, an array of things edible. But each expresses these attachments in diverse cuisines, presentations, and applications that articulate "place" and "locality" in ways that vary with the performance, the context, and the diners. In each iteration, the distinctiveness of place shifts with respect to the social relations of interlocution: Italian and Pan-Asian cuisine can also be the Piedmont's "local foods"; strawberries bespeak "North Carolina" in May when served in Manhattan; savory porchetta over polenta might evoke grits and smothered pork chops.

I do not mean to disparage these efforts, or dismiss the notion that taste is a constitutive feature of place. Rather, these examples suggest the complexity of articulating locality, and of characterizing its qualities with respect to taste, food, and culinary practice. "Local food" operates as a "representation of space" in these performances; that is, it provides a conceptual model meant to promote or direct the production of social space. It orients diners, consumers, and producers to the spatial character of their practice as "local" (as opposed to "cosmopolitan," 
“international," "traditional," among possible spatiotemporal possibilities). These complexities suggest we need to be careful in specifying: what a taste of the land, or territory might amount to, given how highly contingent these "places" are; as well how a taste of such a place might be framed (e.g., as a material feature of regional ecologies, a respect for culinary traditions, or trust in a community of purveyors to provide good meats and produce). How do such relationships constitute "place," and what it is about places that becomes characteristic of the foods procured and purveyed in them?

\section{HERITAGE PIGS: A SENSORY PERSPECTIVE}

The Milltown Farmers' Market requires that all market vendors produce everything they sell. This stipulation contributes to the social dimensions of "place," helping to sustain a sense of what is often described as "connection" between farmers and consumers - and food — very much along the lines promoted by Berry. The social activity of the market, including conversations that range from the health benefits of products, to agricultural techniques, to recipes, is itself discussed by vendors. These discussions include criticisms of the very ethos of creating connections between farmers and customers. As one food activist put it to me, the Milltown Farmer's Market is a place where customers "put two little tomatoes in a basket next to an egg, and then socialize a lot," a well-established critique of the elitism that embeds the sociality of such "connections" in the food itself. Nonetheless, such venues, as well as recurring events in the region such as the Annual Piedmont Farm Tour (sponsored by the Carolina Farm Stewardship Association) or the Farm-to-Fork Picnic (sponsored by the Center for Environmental Farming Systems), help to articulate a sense of place through food among those committed to "local food." These venues work to develop a kind of "sensory field," in which perceptual qualities like health, well-being, social responsibility, and connoisseurship are elaborated. What other qualities of the place constituted by these sociomaterial, or natural-cultural connections might be situated in this place-based sensory field?

Pigs themselves make important contributions to this sensory field. When I asked Pierson what makes the Ossabaw a distinctive breed, she said the standards to which breeds are held might be defined in terms of not just size, appearance, and behavior, but taste. Pigs, she notes, are monogastrics ("like us" she says), not ruminants, and therefore "they are what they eat." The taste of the animal will therefore directly reflect the seasonality — and locality — of what it consumes. "If you feed pigs pumpkins in the fall, they'll taste like pumpkin," Pierson says. 
Such claims about taste, while by no means typical of pastured-pig farmers in the Piedmont (most of whom are new to raising hogs outdoors, and animal husbandry practices more generally; and have less experience dealing with restaurants interested in distinct flavor profiles than Pierson) are supported by a range of regional institutions. Many restaurants support "local pork" for the tastes it offers. Interest groups and academic agencies, like the American Livestock Breed Conservancy in Pittsboro, and the Center for Environmental Farming Systems in Goldsboro, promote outdoor-raised pigs and specialty breeds for the qualities, like taste, these practices support. Further, there is a growing literature in "meat science" that presents intriguing findings about "local pork" and taste. Comparing the taste of Ossabaws raised on a diet of hardwood forest mast (e.g., acorns, hickory nuts, and the seeds and fruits produced by woody plants) with those raised on corn and soy, Talbott and colleagues report that forest-finished Ossabaws were judged (by a "three-member, highly trained sensory panel") to have a "deeper, more complex flavor." At the same time, the judges of this "deeper" taste, report to a high degree that such pigs have what is called (by pork industry standards) an "off-flavor," a category labeled "dark turkey meat" in meat science. To reconcile this apparent discrepancy (pork that tastes so good, that it tastes bad, or "off," the technical term for which in the food taste biz is: "funky"), Talbott et al determine that "For nichemarket applications, a new 'On Flavor' classification may be required to distinguish differences in conventional sensory models" (Talbott et al. 2006:189-190). This conclusion is a fascinating commentary on the cultivation of animals and tastes together, as innovative sensory features of a "local" landscape. At issue here is an understanding not just of how taste reflects an ecological niche; or of how transformations in animal husbandry generate distinctive taste profiles. Rather, we see how the dynamic interrelation of animals (viz., distinctive breeds), husbandry (viz., diets, pasturing, acreage, and "harvesting"), and testing protocols (incl. juiciness, tenderness, chewiness and "pork flavor"; Talbott et al. 2006:190) is transforming the very understanding of what taste is given these "local" innovations. The taste of monogastric pigs may express the conditions (material, social, and otherwise) of their production in a "local place," but we need to remake our understanding of what the taste of pork is to appreciate that "on flavor" "pork taste." An appreciation of this innovative taste - a capacity for discernment, both objectified and subjectified - is, therefore, a dimension of a reconfigured sensory field entailed in the (re)production of pigs in a local landscape.

If these findings in the husbandry and meat science of pigs are components of the elaboration of locality as a sensory field, so too are culinary practices particular 
to pork. The taste-testing protocols by which pigs are evaluated use chilled loin chops as a sample (Talbott et al. 2006:187). This is the standard cut adopted by the niche-pork industry, first established by Niman Ranch; "the company takes a loin chop from every shipment from every farm and grills the chop to be sure it meets Niman standards" (Behr 1999:14). Pierson, too, wants the Ossabaw to be recognized as a breed that will incorporate standards that include a "long, lean, loin" that is still "well-marbled" with fat, as this is what her restaurant chef clients most desire.

Although the loin chop is highly profitable, and marketable, Ossabaw pigs are known (in part) for a genealogy that links them to ibérico pigs from Spain, pigs that are renowned for their superior hams. Currently, most of the ham (i.e., pork leg) produced by Pierson's pigs end up ground into sausage, because of the costs in time and labor of processing hams, and the versatility that grinding pork into a range of sausages affords. But occasionally Ossabaws - and especially Ossabaws bred with other varieties of pig - are used to produce hams. This spring, I attended a ham tasting held at a wine retailer, at which wines were paired with hams made from Haw Branch Ossabaw crossbred pigs, that had been wet-cured and smoked by a local chef. I want to examine this marketing event in some detail, as it demonstrates some ways that pigs (and the people who love them) help constitute "local" place as a sensory field.

\section{“A CURIOSITY FOR CURED MEAT"}

This event charged customers a modest fee to sample foodstuffs. Not surprisingly, the 30 or so attendees were largely affluent; but included among these were a few people at lower echelons of the restaurant business (i.e., not chefs), many of whom were friends of the wine and meat purveyors. Food production processes were framed in the remarks of the wine merchant and ham producer in a manner indicative of wider patterns of place-making activities characteristic of the "local food" community in the region.

The wine buyer introduced the event noting that links between taste and place are relevant to the store itself. The walls of the shop are lined with large photos of vintners from Europe who, "are working on a small scale to support sustainable agriculture. This is exactly what we want to do - we want to do with the wines that we carry, buy things from small farmers from around the world who are concerned about protecting their own wine traditions, in their own homelands."

Here, the category of locality is invoked as an ideological commitment (supporting "sustainable agriculture," "small farmers" "protecting . . . wine traditions"), 
as well as a transposable framework, in which "the local" is a quality that can be found in practices around the world, extracted from other "homelands," and deployed in any spatial context. In this way, "the local" becomes a discernible property of practices that can be enacted anywhere. "Local" European wines are available in the Piedmont.

Next, the chef who prepared the hams introduced the tasting, and Pierson herself, to the crowd. "Thanks so much for coming out," she began, "It's great to have the support and curiosity in cured meats, um, that are done locally." She tells us that the ham was made from an Ossabaw Cross, adding that Pierson, "has been at the Milltown Farmer's Market for-five years now? ... She's actually moved her farm from Mill Creek out to - is it Pinelands? So, Kate, thanks for raising the hog, and, what is an Ossabaw Cross?"

Before I get to Pierson's response I want to note that this off-the-cuff introduction incorporates the themes developed here: it links a series of places across the Piedmont (the market, the farm, "Mill Creek" and "Pinelands") with the animals raised on the farm, and — crucially — includes the audience within this sensory field: "It's great to have the support and curiosity in cured meats . . . that are done locally." Taste - here a community interested in a specific taste, presumed to have a regional relevance - is expressed as a feature of locality.

Here is the response Pierson gave to the question, "and, what is an Ossabaw Cross?":

Pierson: Our farm is now on huge acreage where we raise a lot of different animals, but the pigs are still sort of carrying the name and getting further and further known. A purebred Ossabaw Island Hog has become of interest to a lot of people across the country_ —it's a smaller, long-legged prick-eared, furry funny little black hog with white joints. But it's not very big, it's not a very easy animal to raise or market. It's a little wild, a little wily, they're very smart, very interesting, but kind of small, and they have a particular kind of fat that's actually really hard to make bacon and sausage and things like that with. So what I did was crossed it, developed a boar line and a sow line, and I actually have a breeding herd of a 50/50 cross between that, the Ossabaw island hog, and a five-way old-timey cross called the Farmer's Hybrid. And that ended up being a great part of our marketing strategy. I can do all the things that I want to do with fresh ground product and hams and loins and things for the restaurants in this area, and I have a fast-growing larger-type very colorful hog, with all the fun attributes of the Ossabaw, like sort of better-for-you fat profile and incredible flavor that you're tasting. 
(audience) Has anyone else done this cross?

Pierson: Not that I know of, but people buy them from - or buy the purebred ossabaw and try crossing them on other things like the Duroc or Berkshire-I don't think that would work very well, but a leaner-type hog.

(audience) So you're the first one to do this cross?

Pierson: The first one to think of it as its own breed, and really raise it year after year and keep a breeding herd, and play with it a little bit — so.

(audience) I think it make's a darn good ham (laughter).

\section{TELLING SKILLS}

There is a much to say about this impromptu account of local pig production at Haw Branch. This is the kind of story that Pierson, her staff (and myself) tell in numerous settings. The Ossabaw Hog, from which the Ossabaw Cross derives, has its own complicated narrative history. As already noted, the Ossabaws raised on Pierson's farm are said to be descendants of a group of ibérico pigs, originally brought to the New World in 1539 with De Soto's conquistadors. Abandoned, or perhaps shipwrecked, on the Atlantic Coast, a feral colony of these ibérico's survived in isolation on the Sea Island of Ossabaw, off the coast of Savannah, Georgia. The island remained largely undeveloped through the end of the 20th century, and Ossabaws adapted the characteristic qualities of an "insular breed"; they are small in stature, yet possess a remarkable ability to store fat. This remarkable ability also produces a tendency to develop Type-2 diabetes, which made them of interest to medical researchers. Moreover, the state of Georgia wanted to exterminate these "wild, wily" pigs, because they were destroying threatened loggerhead turtle nests. Thus, a group of 23 pigs were imported for an NIH research study in Columbia, Missouri. From there, Ossabaws made their way to the program in swine husbandry at North Carolina A and T, and so to Pierson's farm (Kaminsky 2005).

But note that what Pierson concentrates on in her comments to this group that has come to taste hams, is what I would call her "farming skill," incorporating a number of distinct, if related activities. The notion of "skill" (Ingold 2000) is important, as skills are embodied dimensions of a sensory field. "The breeder's skilled vision is never detached from a certain amount of multisensoriality" (Grasseni 2004:41) Such skills are ways of grasping and integrating knowledge, technical ability, and bodily activity into a locale. ${ }^{5}$ Such a "field" is not merely a technique deployed in a given time and place, but a mode of activity (or spatial practice, in Lefebvre's terms) through which time and place are (re)produced. Beyond animal husbandry, Pierson's "skills" cover a range of sensory modes of "knowing." 
For example, she offers an understanding of the "personality" characteristics of these pigs — wild and wily, smart and "funny" — features of Ossabaw temperament often discussed on the farm. Sometimes these qualities are seen to be an expression of the narrative history described above; a wild, wily, smart, little pig that got that way as an adaptation to the limited resources of their island habitat. At other times, these qualities are thrown into relief with reference to the challenges of breeding Ossabaws. An essay (by another pig breeder) on "The Unfortunate Demise of the Ossabaw" describes the Ossabaws this way:

Ossabaws are a feral breed of hogs. They are small, difficult to manage and, for feral pigs, very lardy. All those traits work against any commercial exploitation: "small" means slaughter will cost too much per pound of pork, "difficult to manage" implies expensive and irritating and "very lardy" means you've got unusually lardy carcasses (Wooly Pigs 2009).

My point here is not only that "wild and wily" with "a particular kind of fat" might also mean "difficult to manage" and "lardy" (a characterization Pierson forcefully rejected) but also that the characteristics of the Ossabaw (whatever their origin, and however positively or negatively they are described) are never neutral, "objective" features of "animal behavior," or "breed standards." Rather, these are dimensions of the skills needed to husband them. Indeed, "wily" and "difficult" might be the exact same qualities, but their presence in Ossabaws is an expression of Pierson's sensory skills in raising her animals. "Behavior," then, is a potent admixture of colonial narrative, natural selection, and farming technique located in place - or perhaps, a trajectory of places (from Spain to Ossabaw to Mill Creek to Pinelands and ham tasting). This narrative account of the breed also configures place as a representational space in which the Piedmont becomes a "locality" by virtue of its narrative connection to similarly "tellable" places. To tell this story as an account of how Ossabaws become a "local pig," Pierson's skills are required to successfully make the region into a place habitable by Ossabaws (and those who would consume them), and so recognizable as a place with this critical "local food." Such narratives are a striking way in which pigs and pork provide a novel "representational space," a way of imagining new spatial possibilities for inhabiting the Piedmont as a place, often by residents who are relatively recent arrivals to North Carolina, ${ }^{6}$ with little connection to past modes of living here.

Critical to this mixture, and at the core of Pierson's technique and her story, is the breeding process she describes. Her description of the distinguishing physical characteristics of the Ossabaw ("long-legged, prick-eared, furry ... black hog with white joints") refers to those features of hogs that are not simply descriptive 
terms, but definitive attributes that serve to establish these animals as a breed. Ear shape, height, color, each are distinctive "standards," features necessary to the recognition of a breed. Pierson goes on to describe the ways that this now registered, and standardized breed (American Livestock Breed Conservancy 2010) has been crossed with the Farmer's Hybrid to produce, not just an Ossabaw Cross, but "a breeding herd of a 50/50 cross." The specific "standards" of the Ossabaw Hog breed are germane in so far as they become expressed, not just in an animal, but in a breeding herd - that is, as the expression of a specific farming skill, a practice that links knowledge of animals, their histories and possibilities, with a method for perpetuating - literally reproducing - their desired qualities over time. Although the Ossabaw Cross is not the only line of animals being raised on Haw Branch, and any kind of pig (e.g., Tamworths, Gloucestershire Old Spots) might be processed and sold, there is a significant effort made by the Haw Branch staff to monitor the reproductive lives of pigs. Sows are moved according to how recently they have given birth to assure that they are fattened up sufficiently for lactation after they have farrowed (i.e., had litter of pigs), yet do not get so obese that they are unable to reproduce once their litters are weaned. Pigs are moved from their mothers when they are weaned - and these "teenagers" as they're called, are designated for breeding stock, or sent off for fattening. As one staffer put it, "we'll decide to keep these and make 'em sows instead of sausage." These daily practices of adjusting feed, moving animals, sorting offspring, etc., does not make this kind of farming an exacting science of breeding: as one staffer said, “we'll pretty much sell any kind of pig we raise." But it does make breeding an expression of a skill, a multisensory set of capacities that allows the process as a whole to be reproduced in a distinctive locale, in space and time.

Note, moreover, that the pig provides an anchor to these diverse skills. The animal itself is at once a model and objectification (or representation) for how place should be organized, and a representational form that embodies an imagined mode of inhabiting "place." The Piedmont becomes a place with a distinctive (if fabricated) heritage, of farming, breeding, and marketing. The pig permits places to be reinhabited through imagined connections to an alternative past.

\section{PORK EDUCATION: DEVELOPING DISCERNMENT}

All of these skills point toward the effective consumption and, more specifically, eating of these pigs. ${ }^{7}$ Careful attention to behavior and breeding is undertaken because a commitment to animal welfare, breed revitalization, and sustainable land management (enterprises central to the daily activities of Haw Branch) depend on 
the specific orientation of these skilled practices toward the most productive and profitable ways to eat pork. In production, this means the creation of an animal, the Ossabaw Cross, a hybrid of a hybrid - a revitalized breed "crossed" with a well-established hybrid (the Farmers Hybrid, the line promoted by Niman Ranch and its pastured-pig farmers) — that has a number of qualities that are fully realized when the Cross is eaten. Fast growing and large, they produce portions that satisfy what consumers - especially chefs - want; and with a fat profile (higher in Omega-3s than Omega-6s, hence cholesterol inhibiting) that is good for you, and good (or is it "funky"?) tasting. These features of an Ossabaw Cross demonstrate most clearly how concrete farming "skills" entail the dynamic constitution of a (multi)sensory field; and so, they are central to the process of "making pigs local." The Ossabaw Cross is an amalgam of animal husbandry, marketing strategies, and social networking (and perhaps cardiology) — abstract principles of "science" that are grounded in sensory skills. These include the breeding practices discussed, as well as an appreciation of how restaurants portion their meat, and, of course "incredible flavor," all at once immediately sensible attributes of the Cross, and qualities whose appreciation requires careful discernment. But it is by means of the edibility of this pig, the Ossabaw Cross, that the various attributes of the narrative, the techniques, the strategies, and the scientific know-how that "go into" local pigs achieve their integration. Thus, it can equally be said (with apologies to Berry) that "Agriculture (or animal husbandry) is a culinary act." Pigs are reconfigured to match the gustatory preferences of a consuming public. ${ }^{8}$ It's only by virtue of the exquisite taste of the Cross ("bred" to satisfy the demands of chefs and consumers for flavor, health, and apportionment) that the storied past of the Ossabaw, the skilled breeding, and pastured lifespan of these animals, and the pleasures of a rich, satisfying meal are emplaced in a unified sensory field.

The reciprocal sensory dimension of the production process, then, is not simply "the market" or consumption, but a discerning public understood to be (but also be made to be) knowledgeable about and desirous of good pork. ${ }^{9}$ Discernment is critical to the relationship between consumers and producers, and further grounds qualities of taste in a material landscape, and specific places. When purveyors identify "a curiosity in cured meats ... done locally" as part of their successful marketing practices, they are positing a capacity, at once subjective and material, to appreciate qualities in pigs in particular places. Lauding the "off flavor" of Ossabaw pork as a desirable quality, makes an appreciation of innovative tastes part of a reconfigured sensory field that (re)produces pigs in a local landscape. In both cases discernment is objectified (materially embodied in the pig) and subjectified 
(expressed in the experience of consumers). It might be presumed (to a degree), but it can also be cultivated; indeed, the two go together, as a given "curiosity" is critical to appreciating the taste innovations that "local foods"-like the Ossabaw cross - generate.

In this way, this carefully selected animal, raised to meet the requirements of a discerning (if diverse) ${ }^{10}$ public, is a kind of a switchpoint between material conditions (of production and consumption, incorporating species rotation, and growth rates, portion size and fat content) and symbolically qualified characteristics (incl. a colonial narrative constituting heritage, a "wily," "funny" hog, and a deliciously "funky" fatty pork). The Ossabaw Cross reminds us that these are not distinctive "levels" of appreciation. They are copresent dimensions of a concrete reality - a living, breathing, meant-to-be delicious pig - embodied and experienced in the world. This embodiment entails a coordination of skills deriving from diverse sensory practices (observing, feeding, crossing, selecting, sorting) fully realized in sensory qualities of "taste" specific to that range of skills. The "locality" of such pigs, and so the development of "taste" as a dimension of "place" that they exhibit, is an expression of the ways this highly innovative, wholly contemporary hog, is bound to the distinctive place constituted by this sensory field, a way of seeing, feeding, breeding, and finally tasting an animal.

Equally clear is that among the skills that are the foundation of this sensory field are many forms of consumers' discernment. The materiality of the natural-cultural processes that establish the sensory field is rendered as social value through the taste of this pork, a taste that is only recognizable as a value when it has been cultivated through processes of skilled appreciation. The culinary discernment that marked the ham-tasting event is repeated in venues across the region. Indeed, selling pork at the Milltown Farmers' market, where the clientele is (largely) committed to "local food," and typically exhibits a "curiosity" for pastured pork, is routinely an exercise is cultivating discernment among already discerning consumers. At a typical market, vendors offer advice on how to prepare pork, propose alternative cuts for various dishes, retell the many narratives of the Ossabaw to culinary tourists, and extol the virtues of small, well-marbled pork chops. Cultivating discernment helps generate the value held to inhere in such "local" pork.

Pork tasting (at least in the form of ongoing barbecue conversation) is the birthright of all North Carolinians. The Farm-to-Fork Picnic, held in the early summer, displays numerous ways of cultivating discernment in pork. This event couples chefs and farmers from the Piedmont, and charges customers $\$ 60$ to attend. The 700 tickets available routinely sell out weeks before the event, which bespeaks 
both the affluence and locavoracious interests of the community. The chefs and restaurant staff with whom I spoke were all impressed with the range of pork dishes available at the picnics, and the quality of the pork offered. When I asked why they thought there were so many pork dishes, many on the staff said "It's North Carolina, you have to serve pork." Fair enough; but it is worth noting that, while only one vendor offered whole hog barbecue, the other pork dishes included cochinita pilbil roasted in banana leaves, artisanally cured head cheese, and slowbraised and grilled pig tails. Such offerings depend on both an interest in things pig_ “It's North Carolina, you have to serve pork" — but show an interest, as well, in using that a priori desire as a foundation from which to develop new interests, expand tastes, and cultivate new forms of discernment. Many professional cooks see the revitalization of heritage pigs as an opportunity to promote precisely such new forms of discernment — or, as they often put it to me, "to educate the public." Niche-market pork's role as an icon of discernment produces some intriguing and complex culinary problems. At Monsoon, for example, the pork shoulder one month was slowly braised and simmered in a coconut sauce. The item was never a big seller, a fact I discussed with the manager one day. "Yeah," she said, "customers don't even know what it is. We need to educate people about it."

This comment points toward a specific paradox in cultivating discernment characteristic of heritage pork. All of the chefs I spoke with love this product. The line cooks and prep cooks where I worked said their favorite dish on the menu was pork shanks - and told me of a shank recipe so delicious that it was stolen by a former line cook for his new establishment. However, many of the chefs I spoke to said that they couldn't make money on pork dishes. "People don't want a pork chop when they are going to spend a fair amount of money on dinner. ... Even though we're in North Carolina, people don't think of pork when they think of fine dining," one hotel chef told me. Nonetheless, he offered local breakfast sausage free of charge in the breakfast served to hotel guests to attract them to dinner. Indeed, all of the pork he served was from Haw Branch, curing his own bacon and blending his own sausage from Pierson's pork. The pork chops at Monsoon were monstrous double-cut portions, carrying a hefty price tag. The sous-chef told me they had been butchered and trimmed improperly in the past ("they left too much bone on the chops"), but were now wellcut by the processor. Still, he said, they couldn't make money on them - this season, they would just break even. "It's important that we keep it on the menu," though, he said. "We want people to see that we support local pork." It may be the case that there are profit motives that shape this practice of losing money on pork, or even giving it away; the sign exchange value 
of a loss leader (pricey though it may be) could yield higher profits in the end. But in their own views, restaurants support "local" pork because they understand the cultivation of discernment to be central to their operation. "Educating diners," as a great many chefs put it, is part of what restaurants do. The economics of their use of niche-market pork is driven by this interest in promoting an appreciation of good things.

How might we characterize this discernment? What are the conditions that make such discernment possible? What kinds of "tastes" are promoted when "educating diners"? And how do pigs and pork facilitate these practices? These forms of "education" and discernment should be linked to the "curiosity in cured meats" discussed earlier, the always-already interest in pork in Carolina, to see how these prior interests and new modes of "education" contribute to a sense of "the local." Discernment depends simultaneously on a "given" interest, an appreciation for certain qualities (think bacon and barbecue) among which degrees of discrimination and distinction (unctuousness, "depth," “funk") can be introduced. That is, discernment requires both continuity and transformation. This point was illustrated for me in discussions about cured pork. Pierson has had an interest in working with a partner to develop a facility for curing meats. Some older businessmen, who had a long history of curing and marketing country hams in the Piedmont, were invited to Haw Branch to speak with Pierson. When I spoke with them they said they had raised pigs since they were young, but they realized "ham was the thing," and they got out of the pig business to concentrate on curing country ham from pigs raised by others. When I heard Pierson talk with the potential partner about these men's experiences, she was unhappy with their claims. For her, the disconnection between pigs and hams was problematic. "These guys are just supporting the lousy genetics of industrial pigs," she noted. Although her objections were at the level of animal welfare and farming techniques, the partner — who was working closely with a local chef to develop curing recipes - was uncomfortable with "country ham." He preferred to develop a line of prosciutto, culatello, and Tuscan sausages. "We don't really want to produce country ham," he said, "we're trying to cure artisanal meats.”

This discussion indicates the value that discernment plays in shaping a taste for pork, which is to say in characterizing pigs as "local." The shift from "country hams" to "artisanal meats," not identical, but akin to the shift from "industrial" to "pastured" pigs, requires already existing conditions of possibility that permit forms of innovation to emerge. It is only the compelling interest in pigs and pork (exemplified, for many, by industrial pork, and "commodity" country hams) that 
allows the introduction of novel categories ("pastured," "artisanal," and "local") to be understood and appreciated. ${ }^{11}$ These modes of continuity and transformation are requisite features of any form of discernment. Note, too, that the shift from "country" to "artisanal" correlates with how the adoption of revitalized animals, and techniques of breeding permit the reimagination of emplaced connections to an alternative past. Inhabiting place in a "local" fashion is a matter of innovation, never just continuity. In all cases, narratives of discernment provide a means of underwriting the value of "the local."

\section{CONCLUSIONS}

Highlighting the role of discernment and the integration of sensory fields should alert us to social concerns that are a consequence of this way of thinking about taste and place. For if place is made through the recognition of critical qualities (skills and tastes, objectified and embodied), its important to ask what, and more importantly, who, is not recognized in such place making. As I suggested, issues of race and class are uneasily incorporated into the politics of "local food." The historical prominence of African Americans in hog production in North Carolina, for example, is well established. What is less clear is the role that black farmers will play in producing "local" "pastured" pigs. A number of African American farmers and African American institutions, such as Historically Black Colleges, in North Carolina have ambivalent relations to these categories and processes. Although there has been outreach to black farmers, and by black agricultural extension agents, to facilitate and promote pastured-pig production, a good deal of skepticism, if not antagonism, remains. African American farmers often reject the categories of "local" and "cooperative," even as their "traditional" practices include annual hog killing and processing among small groups of neighboring family farmers. In short, their practices are "local" and "cooperative" even if they do not embrace these categories (or enjoy recognition for their practices). The uneven adoption of these categories demonstrates that "local" is not simply an existential condition of being in a place, it is a specific orientation to how space is produced. "Local food," then, is a way of evaluating sociospatial relations. ${ }^{12}$

Nonetheless, the ambivalence surrounding these categories, persons, and practices demonstrate that place is a way of making, an active process, open to innovation and contestation. Place is never a given. "The local" works to make sociospatial relations, and so to evaluate practice. This analysis implies that we can think of a taste of place as promoting transformation and not just preservation (as much of the language of Slow Food [Petrini 2006], e.g., implies). 
Indeed, the necessity of discernment to any appreciation of such tastes indicates that taste is tied to the promotion of emerging sensory fields, as new modes of discernment refine an appreciation of the given qualities of any place. Such “tastes" cannot be reduced to specific times and places. Rather, a concern with the connection between taste and place-grasped as a sensory field, producing space - helps us better understand how places are made. Greater attention to the possibilities, and limitations, of these wider activities, and the array of elements (culinary, animal, commercial, and technical) that participate in making place may help us appreciate the specific qualities (both recognized and excluded) of "the local."

\begin{abstract}
This article offers an attempt to characterize the relationship between "taste" and "place" as cultivated and embodied in the production, circulation, and consumption of pasture-raised pork. I focus on the Piedmont region of North Carolina, and offer ethnographic evidence drawn from working with farmers, chefs and restaurant workers, as well as consumers at farmers' markets to give substance to these discussions. The argument problematizes the category of "local food," to interrogate the very notion of "place" and its many "tastes" (and other experiential qualities) with respect to the remaking and remapping of food production in the Piedmont. "Local food" is widely celebrated in this region, and pastured pork is a critical index of this "locality"; but here I ask how place itself is constituted, assigned concrete, experiential qualities, and so grasped in social practice. More than an attempt to specify the qualities of "the local" and their relationship with regional foodways, this article is concerned with the process that Lefebvre calls "the production of space." [food, animals, place, taste]
\end{abstract}

\title{
Notes
}

Acknowledgments. I received invaluable advice on this article from a number of colleagues. In particular, the comments of Misty Bastian, Heather Paxson, Kathy Rigby, Rachel Reynolds, andabove all - Chris Nelson, were a source of inspiration. I owe an enormous thanks to the many farmers, chefs, and customers I have worked with since early 2009. In particular, the farmers and staff at the market I have called the Milltown Farmers Market have been incredibly generous and welcoming. The manager of the market has taken a good deal of her time to talk about a range of food issues with me, and I am grateful for her continuing interest in this project. The staff at the restaurant I have called Monsoon here were equally receptive to my intrusions into their kitchen. I learned a great deal from all of them, and hope they know of my abiding respect for them. Above all, I am thankful beyond words to the farmer I've named Kate Pierson here, and to her staff and family at her farm. It has been an intellectually, physically, and emotionally rewarding (and often exhausting!) experience working and learning alongside Kate and her staff. They have not only enriched my anthropological practice, but my very life, in ways I am still coming to understand. My undying thanks to them all.

1. Both North Carolina and Iowa, the two leading producers of pork nationwide, are seeing a rapid growth in pasture-raised pork production. Although the complex relationship between 
industrialization and niche-market pork is beyond the scope of this article, this growth suggests that a familiarity with industrialization, and a long-standing interest in consuming pork (and presumably similar agricultural products), can stimulate the development of "local" economic activities.

2. I've used pseudonyms for all the people and institutions named here.

3. Although Lefebvre writes about the "production of space," I refer to "place" throughout this article. Places are typically characterized by the presence of concrete qualities, and Lefebvre's model incorporates an understanding of how the production of space imbue spaces with experiential features.

4. A highly contested term (Kloppenburg et al. 2000).

5. These skills also have a political economic point of reference. Pierson contrasts her skilled management techniques with confinement operations where, in her view, no skill is required as "pigs are raised like car batteries." Another farmer who once worked in confinement said the work "turned me into a machine" through constant grueling, powerwashing that did not develop husbandry skills, or even enhance his physical strength but, rather, "broke down my body."

6. North Carolina has the third fastest growing population in the United States, much of the in-migration concentrated in the Piedmont.

7. My thanks to Alex Blanchette for pointing out the many other ways that pigs can be, and are consumed.

8. The (re)organization of pig breeding, and the selection of market pigs to meet consumer interests is a feature of production that every pig farmer I have spoken with has acknowledged. This consumer driven production — called "market response agriculture" in the agricultural community — has lead many farmers to transform their operations, from feed to breeding stocks.

9. “Discernment" has parallels with Bourdieu's understandings of "Distinction" (Bourdieu 1984), but is not identical to it. There are consumers for whom the taste of niche-market pork embodies their "distinguished" class standing; but there are any number of consumers of this same pork who speak of it as "just like my grandfather's pigs used to taste" and so see their tastes as a mode of affiliation with tastes that counter hierarchies of class distinction; such tastes are not simply dominated by a dominant aesthetic (Bourdieu 1984:41). This reveals the ways that Bourdieu's sociocentric analyses fails to incorporate a concern for the materiality of the objects he describes, which remain essentially empty forms animated by class judgments. The taste of pork is not so easily neutralized.

10. See my conclusion for a discussion of who constitutes this public.

11. I would not say that the presence of industrial pork "creates" the Piedomont's (or Iowa's) interest in "local food"; but I do think the prominence of pork production in the region creates an awareness of pork that allows it to become a central, even exemplary "local food."

12. These dimensions of "making pigs local" are the focus of my ongoing research.

Editors' Note: Cultural Anthropology has published a number of essays on food cultures. See, for example, Nancy Ries's "Potato Ontology: Surviving Postsocialism in Russia" (2009), Heather Paxson's "Post-Pasteurian Cultures: The Microbiopolitics of Raw-Milk Cheese in the United States" (2008), Mark Liechty's “Carnal Economies: The Commodification of Food and Sex in Kathmandu” (2005), and Carolyn Rouse and Janet Hoskins's "Purity, Soul Food, and Sunni Islam: Explorations at the Intersection of Consumption and Resistance" (2004).

Cultural Anthropology has also published a number of essays on "place," including, Paolo Favero's "Phantasms in a 'Starry' Place: Space and Identification in a Central New Delhi Market” (2003), Andrea Smith's "Place Replaced: Colonial Nostalgia and Pied-Noir Pilgrimages to Malta" (2003), and Andrea Muehlebach's "'Making Place' at the United Nations: Indigenous Cultural Politics at the U.N. Working Group on Indigenous Populations” (2001). 


\section{REFERENCES CITED}

American Livestock Breed Conservancy

2010 Breed Information-ALBC Conservation Priority List. http://www.albc-

Barham, Elizabeth usa.org/cpl/wtchlist.html, accessed May 1, 2010.

2003 Translating Terroir: The Global Challenge of French AOC Labeling. Journal of Rural Studies 19:127-138.

Bourdieu, P.

1984 Distinction: A Social Critique of the Judgement of Taste. London: Routledge.

Behr, Edward

1999 The Lost Taste of Pork: Finding a Place for the Iowa Family Farm. The

Berry, Wendell Art of Eating 51:1-20.

1990 The Pleasures of Eating. In What Are People For? Pp. 145-153. New York: North Point.

Casey, Edward

1998 The Fate of Place: A Philosophical History. Berkeley: University of California Press.

Dover, M., and L. M. Talbot

1987 To Feed the Earth: Agroecology for Sustainable Development. Washington, DC: World Resources Institute.

Favero, Paolo

2003 Phantasms in a "Starry" Place: Space and Identification in a Central New Delhi Market. Cultural Anthropology 18(4):551-584.

Grasseni, Cristina

2004 Skilled Vision. An Apprenticeship in Breeding Aesthetics. Social Anthropology 12(1):41-55.

Honeyman, M. S.

2006 The United States Pork Niche Marketing Phenomenon. Journal of Animal Science 84:2269-2275.

Ingold, Tim

2000 Perception of the Environment: Essays in Livelihood, Dwelling and Skill. London: Routledge.

Iowa State University

N.d. Hog Reference List. http:/ / econ2.econ.iastate.edu/faculty/lawrence/PorkStat/ porkstat.htm, accessed May 15, 2010.

Kaminsky, Peter

2005 Pig Perfect: Encounters with Remarkable Swine and Some Great Ways to Cook Them. New York: Hyperion.

Kenner, Robert, dir.

2009 Food Inc. 94 min. Magnolia Home Entertainment. New York.

Kingsolver, Barbara

2008 Animal, Vegetable, Mineral: A Year of Food Life. New York: Harper Perennial.

Kloppenburg, Jack, Jr., Sharon Lezberg, Kathryn De Master, George W. Stevenson, and John Hendrickson

2000 Tasting Food, Tasting Sustainability: Defining the Attributes of an Alternative Food System with Competent, Ordinary People. Human Organization 59(2):177-186.

Lefebvre, Henri

1991 The Production of Space. New York: Wiley-Blackwell. 
Liechty, Mark

2005 Carnal Economies: The Commodification of Food and Sex in Kathmandu. Cultural Anthropology 20(1):1-38.

Merleau-Ponty, Maurice

1962 The Phenomenology of Perception. London: Routledge and Kegan Paul. Morgan, Robert

1998 Legal and Political Injustices of Industrial Swine Production in North Carolina. In Pigs, Profits and Rural Communities. M. Thu Kendall and E. Paul Durrenberger, eds. Pp. 138-144. Albany: State University of New York Press.

Morrow, Morgan

2005 Marketing "Niche Pork." http://www.thepigsite.com/articles/27/labellingtraceability/1522/marketing-niche- pork, accessed September 21, 2009.

Muehlebach, Andrea

2001 "Making Place" at the United Nations: Indigenous Cultural Politics at the U.N. Working Group on Indigenous Populations. Cultural Anthropology $16(3): 415-448$.

Niman, Nicolette Hahn

2009 Righteous Porkchop: Finding a Life and Good Food beyond Factory Farms. New York: William Morrow.

North Carolina in the Global Economy

N.d. Home page. http://www.soc.duke.edu/NC_GlobalEconomy/hog/overview. shtml, accessed October 16, 2008.

Page, Brian

1997 Restructuring Pork Production, Remaking Rural Iowa. In Globalising Food: Agrarian Questions and Global Restructuring. D. Goodman and M. Watts, eds. Pp. 133-157. London: Routledge.

Paxson, Heather

2008 Post-Pasteurian Cultures: The Microbiopolitics of Raw-Milk Cheese in the United States. Cultural Anthropology 23(1):15-47.

2010 Locating Value in Artisan Cheese: Reverse Engineering Terroir for NewWorld Landscapes. American Anthropologist 112(3):444 457.

Petrini, Carlo

2006 Slow Food Nation: Why Our Food Should Be Good, Clean, and Fair. New York: Rizzoli Ex Libris.

Pollan Michael

2007 The Omnivore's Dilemma: A Natural History of Four Meals. New York: Penguin.

Ries, Nancy

2009 Potato Ontology: Surviving Postsocialism in Russia. Cultural Anthropology 24(2):181-212.

Rouse, Carolyn, and Janet Hoskins

2004 Purity, Soul Food, and Sunni Islam: Explorations at the Intersection of

Schlosser, E.

Consumption and Resistance. Cultural Anthropology 19(2):226-249.

2001 Fast Food Nation. New York: Harper Perennial.

Smith, Andrea

2003 Place Replaced: Colonial Nostalgia and Pied-Noir Pilgrimages to Malta. Cultural Anthropology 18(3):329-364.

Talbott, Charles, M. Todd See, Peter Kaminsky, Don Bixby, Michael Sturek, I. Lehr Brisbin, and Charles Kadzere

2006 Enhancing Pork Flavor and Fat Quality with Swine Raised in Sylvan Systems: Potential Niche-Market Application for the Ossabaw Hog. Renewable Agriculture and Food Systems 21(3):183-191. 
Trubek, Amy B.

2008 The Taste of Place: A Cultural Journey into Terroir. Berkeley: University of California Press.

Trubek, Amy B., and Sarah Bowen

2008 Creating the Taste of Place in the United States: Can We Learn from the French? GeoJournal 73:23-30.

Wooly Pigs

2009 The Unfortunate Demise of the Ossabaw. http://woolypigs.blogspot.com/ 2009/01/unfortunate-demise-of-ossabaw.html, accessed March 10, 2010. 